\title{
DESAIN MEJA KERJA KETUA JURUSAN DESAIN POLITEKNIK NEGERI SAMARINDA
}

\author{
Dwi Cahyadi ${ }^{1}$ \\ ${ }^{1}$ Staf Pengajar Program Studi Desain, Jurusan Desain \\ Politeknik Negeri Samarinda \\ Arfandi $^{2}$ \\ ${ }^{2}$ Mahasiswa Program Studi Desain, Jurusan Desain \\ Politeknik Negeri Samarinda
}

\begin{abstract}
ABSTRAK
Politeknik Negeri Samarinda adalah salah satu perguruan tinggi di Samarinda yang terdiri dari beberapa jurusan dan program studi. Salah satunya adalah Jurusan Desain yang terdiri dari dua program studi yaitu Desain Produk dan Arsitektur. Ke dua Program Studi tersebut masing-masing memiliki gedung perkuliahan. Karena gedung program studi Arsitektur masih baru maka dibutuhkan meja khusus Ketua Jurusan Desain di gedung tersebut.

Tujuan perancangan meja kerja ini adalah untuk melengkapi kebutuhan produk mubel di ruang Ketua Jurusan yang ada di gedung Arsitektur. Desain meja kerja ini menggunakan konsep portable dan sistem lepas-pasang pada bagian-bagian tertentu yang dapat mengatasi permasalahan space ruang kantor dan pintu yang sempit, serta mengutamakan kebutuhan pengguna dari segi fungsi dan estetikanya. Dengan metode perancangan yang dilakukan antara lain; pengumpulan data, analisa data, konsep atau spesifikasi desain, alternatif desain, pengembangan alternatif terpilih, serta desain akhir, maka didapatkan hasil akhir perancangan meja kerja dengan konsep portable bergaya desain modern sesuai kebutuhan dan keinginan pengguna. Dengan dibuatnya meja kerja yang sesuai fungsi dan estetis diharapkan dapat membantu aktivitas kantor harian untuk Ketua Jurusan Desain Politeknik Negeri Samarinda, sehingga tercipta desain yang lebih baik.
\end{abstract}

Kata kunci: desain, meja kerja 
Vol. 2, No. 2, April 2015

\begin{abstract}
Samarinda State Polytechnic is one of the colleges in Samarinda consisting of several majors and courses, one of which is the Design Department, which consists of two courses, namely the Product Design and Architecture. Study Program Product Design and Architecture have each lecture building. Because the building Architectural studies program is still new, the need for a special desk Chairman of the Department of Design at the building.

Work table design objectives are to complement the needs of furniture products in the existing Chairman of the Department of Architecture building. Another objective of this work table design that uses the concept of portable and removable systems in certain parts that can overcome the problems of space for office space and the narrow door, and prioritize the needs of users in terms of function and aesthetics. With a design method of among others; data collection, data analysis, concept or design specifications, design alternatives, the selected alternative development, as well as the final design, the final results obtained design concept portable workbench with a modern design style according to the needs and desires of the users. We make appropriate workbench and aesthetic functions are expected to help the daily office activities to the Chairman of Samarinda State Polytechnic School of Design, so as to create a better design.
\end{abstract}

Keywords: design, work desks

\title{
I. Pendahuluan
}

Politeknik Negeri Samarinda adalah bantuan meja kerja. Meja kerja dapat salah satu perguruan tinggi negeri di Samarinda yang terdiri dari sepuluh jurusan dan salah satunya adalah Jurusan Desain. Jurusan Desain berdiri sejak tahun 2008 dan memiliki dua program studi yaitu Desain Produk dan Arsitektur. Jurusan Desain di Politeknik Negeri Samarinda merupakan jenjang penidikan D3 dengan kompetensi lulusan yang berbeda antara masing-masing program studi. Jurusan Desain memiliki dua gedung perkuliahan yaitu gedung perkuliahan untuk program studi Desain Produk dan Arsitektur.

Meja kerja adalah salah satu komponen yang penting dari setiap kantor. Bahkan, pekerjaan resmi sehari-hari dan fungsi lainnya tidak dapat dilakukan tanpa digunakan untuk menyimpan file dan dokumen, surat-surat penting, untuk menulis dan meletakkan komputer. Meja yang ada sekarang masih memiliki dimensi/ukuran yang besar, sedangkan ruang Ketua Jurusan tersebut tidak memiliki ruang yang begitu luas.

Ketua Jurusan Desain di Politeknik

Negeri Samarinda sudah memiliki meja khusus untuk Ketua Jurusan di dalam ruang Ketua Jurusan yang berada di gedung Desain Produk, sedangkan di ruang ketua jurusan yang ada di gedung Arsitektur masih belum memiliki Meja. Adanya meja kerja ketua jurusan di gedung Arsitektur untuk memudahkan dan membantu pekerjaan ketua jurusan di gedung Arsitektur, seperti menerima tamu, asistensi mahasiswa dan 
Dwi Cahyadi, Arfandi, Desain Meja Ketua Jurusan Desain Politeknik Negeri Samarinda

lain-lain yang berhubungan dengan program studi Arsitektur.

\section{Metode Penelitian}

Dalam perancangan ini dilakukan dalam beberapa tahapan desain secara terus menerus adalahyaitu:

1. Preliminary Design. Yaitu pengumpulan data dan informasi, analisis data berdasarkan konsep desain makro yang meliputi analisis (konsep fungsi, konsep pemakai, konsep pasar, dan konsep produk), penyusunan program desain dan sketsa awal. Yang diawali dengan perumusan masalah, tinjauan pustaka, kemudian disusun spesifikasi desain.

2. Design Development. Pada tahap ini dibuat alternative gambar komponen serta rancangan secara wire diagram dengan bentuk 3D (tiga dimensi). Dari bagan yang ada terdiri dari beberapa alternatif desain yang dilengkapi analisis tiap alternatif. Dari beberapa alternatif akan terpilih desain terpilih, yang akan dikembangkan menjadi beberapa pengembangan desain, sehingga muncul final dresain.

3. Final Design and Prototyping. Dibuat gambar-gambar, yaitu gambar presentasi 3D dan gambar teknik (gambar tampak, gambar potongan, gambar detail dan spesifikasi teknis produk). Tahapan selanjutnya adalah pembuatan komponen-komponen dilakukan assembling (exploded) atau perakitansehingga menjadi produk (prototype)

\section{Pembahasan}

Awal proses desain dengan melakukan analisis aktivitas dan kebutuhan untuk mengetahui apa saja aktivitas yang berhubungan dengan jursan desain. Setelah diketahui apa saja aktivitasnya, maka akan diketahui kebutuhan komponen yang harus ada pada produk. Berikut ini data analisis aktivitas dan kebutuhan yang berkaitan dengan produk yang ditunjukkan dalam tabel 1 , di samping.

Dari analisis aktivitas dan kebutuhan yang terdapat pada tabel 1, maka didapatkan kesimpulan mengenai komponen-komponen apa saja yang harus ada dalam produk: (1) Lemari untuk menyimpan berkas/dokumen penting, (2) Laci untuk menyimpan alat tulis kantor, (3) Space untuk area kerja laptop/ kmputer dan printer, (4) Area datar untuk meletakkan aksesoris pajangan seperti vas bunga, jam dan lain-lain

Analisa ergonomi dilakukan untuk meminimalkan resiko kesehatan dan keselamatan dalam produk yang dirancang. Dengan begitu efisiensi, kesehatan, keselamatan, dan kenyamanan dalam melakukan kegiatan menggunakan produk dapat maksimal. Sedangkan analisa antropometri dilakukan guna mendapatkan dimensi atau ukuran produk yang sesuai dengan tubuh pengguna. Berikut ini adalah 
Tabel .1 Analisis Aktivitas dan Kebutuhan

\begin{tabular}{|c|c|c|c|}
\hline No. & Aktivitas & Kebutuhan & Fasilitas \\
\hline 1. & $\begin{array}{l}\text { Mengetik } \\
\text { Laptop/Komputer }\end{array}$ & $\begin{array}{l}\text { Area kerja } \\
\text { menggunakan } \\
\text { Laptop/Komputer } \\
\end{array}$ & \multirow{2}{*}{$\begin{array}{l}\text { Meja kerja yang } \\
\text { menyediakan tempat } \\
\text { khusus untuk } \\
\text { mengerjakan sesuatu di } \\
\text { laptop/komputer dan } \\
\text { printer }\end{array}$} \\
\hline 2. & Mencetak dokumen/file & $\begin{array}{l}\text { Area datar untuk meletakkan } \\
\text { alat cetak/printer }\end{array}$ & \\
\hline 3. & Menulis / Menggambar & $\begin{array}{l}\text { Area datar untuk melakukan } \\
\text { kegiatan } \\
\text { menulis/menggambar }\end{array}$ & \multirow{3}{*}{$\begin{array}{l}\text { Memiliki ruang atau } \\
\text { area datar yang cukup } \\
\text { luas untuk kegiatan } \\
\text { bekerja seperti menulis, } \\
\text { menggambar, mengetik } \\
\text { menggunakan laptop, } \\
\text { dan untuk meletakkan } \\
\text { pajangan pada meja } \\
\text { seperti vas bunga, jam }\end{array}$} \\
\hline 4. & $\begin{array}{l}\text { Meletakkan } \\
\text { Mengambil laptop }\end{array}$ & $\begin{array}{l}\text { Area datar untuk meletakkan } \\
\text { laptop saat digunakan }\end{array}$ & \\
\hline 5. & $\begin{array}{l}\text { Meletakkan aksesoris } \\
\text { meja (hiasan } \\
\text { bunga/furnitur lain) }\end{array}$ & $\begin{array}{l}\text { Area datar untuk meletakkan } \\
\text { hiasan meja/aksesoris meja }\end{array}$ & \\
\hline 6. & $\begin{array}{l}\text { Mengambil } \\
\text { Meletakkan alat tulis } \\
\text { kerja (pulpen, } \\
\text { penggaris, gunting) }\end{array}$ & $\begin{array}{l}\text { Penyimpanan untuk } \\
\text { meletakkan alat tulis kerja }\end{array}$ & $\begin{array}{lr}\text { Memiliki ruang dan laci } \\
\text { khusus } \\
\text { meletakkan } \\
\text { ATK. }\end{array}$ \\
\hline 8. & $\begin{array}{l}\text { Meletakkan / } \\
\text { Mengambil berkas } \\
\text { dokumen penting }\end{array}$ & $\begin{array}{lr}\text { Ruang untuk menyimpan } \\
\text { berkas/dokumen } & \text { penting } \\
\text { yang berbeda } & \text { dengan } \\
\text { tambahan kuncian } & \\
\end{array}$ & $\begin{array}{l}\text { Memiliki lemari yang } \\
\text { digunakan } \\
\text { menyimpan } \\
\text { dokumen/arsip penting } \\
\end{array}$ \\
\hline
\end{tabular}

titik-titik ke-ergonomisan pada produk, yaitu: (1) Untuk ke-ergonomisan meja saat digunakan terletak pada kaki mejanya, tinggi posisi meja harus sesuai dengan tinggi standar posisi laki-laki dewasa ketika sedang duduk, (2) Ke-ergonomisan pada meja tersebut juga adalah dengan mendesain meja dan mengurangi sudut-sudut tajam untuk menghindari kecelakaan pada saat bekerja pada meja tersebut, (3) Massa berat fasilitas yang ada di meja seperti folder, buku, kertas, dan lain sebagainya tidak boleh melebihi beban yang ditentukan untuk pengguna, (4) Handle yang digunakan pada laci dan lemari secara keseluruhan tidak terdapat bagianbagian yang tajam yang dapat menimbulkan luka, (5) Saat meja digunakan untuk menulis, membaca, menggambar maupun mengetik harus sesuai dengan jarak lihat pengguna yang tidak terlalu rendah dan tidak terlalu tinggi agar badan tidak terlalu membungkuk ke depan, (6) Panjang dan lebar meja kerja harus disesuaikan dengan rentang kedua tangan pengguna saat ke samping dan ke depan.

Berikut penjelasan mengenai anthropometri yang akan diaplikasikan pada produk. 
Dwi Cahyadi, Arfandi, Desain Meja Ketua Jurusan Desain Politeknik Negeri

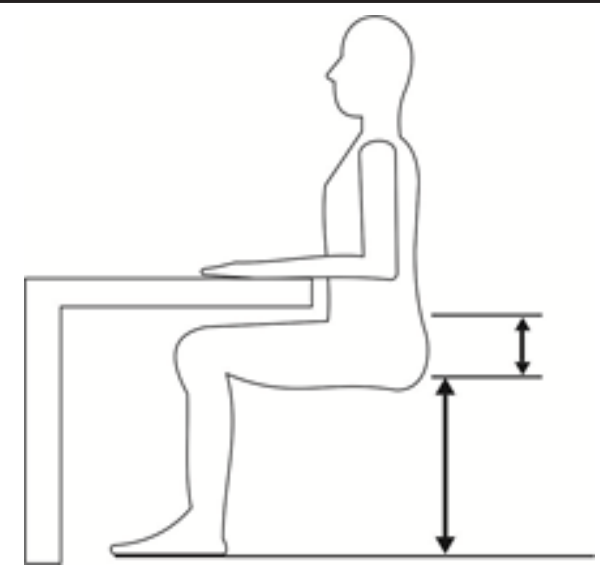

Gambar 1. Tinggi popliteal dan tebal paha

Antropometri yang digunakan untuk menentukan tinggi meja adalah dimensi antropometri tebal paha dan tinggi lipat lutut. Jenis antropometri yang digunakan untuk kelompok pria $50 \%$ persentil, yaitu tebal paha $140 \mathrm{~mm}$ ditambah tinggi lipat lutut $445 \mathrm{~mm}$ sama dengan $585 \mathrm{~mm}$. Perlu adanya penambahan $30 \mathrm{~mm}$ untuk toleransi sepatu, $100 \mathrm{~mm}$ untuk kelonggaran paha pada saat duduk. Oleh karena tinggi paha manusia akan relatif bertambah pada saat duduk menggunakan sepatu yang disebut pengaruh dinamis (dynamic effect). Sehingga total tinggi meja keseluruhan tinggi produk meja kerja yang dirancang boleh kurang dari 70 cm dan tidak lebih dari 76,2 cm.

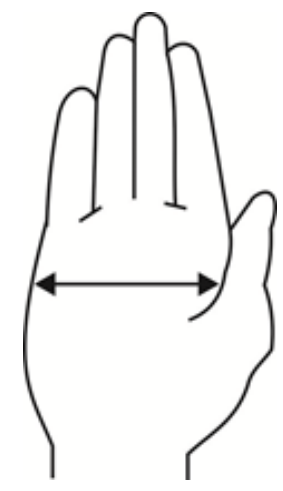

Gambar 2. Lebar telapak tangan
Antropometri yang digunakan untuk menentukan ukuran handle meja adalah lebar telapak tangan. Jenis antropometri yang digunakan untuk kelompok wanita 50\% persentil, yaitu $81 \mathrm{~mm}$. Berdasarkan data dimensi manusia dan ruang interior menurut Panero dan Zelnik disebutkan bahwa dimensi tangan berkisar 8,2 cm. Jadi, dimensi lebar telapak tangan yang dirancang tidak boleh kurang dari 73 cm agar ruang gerak tangan tidak sempit.

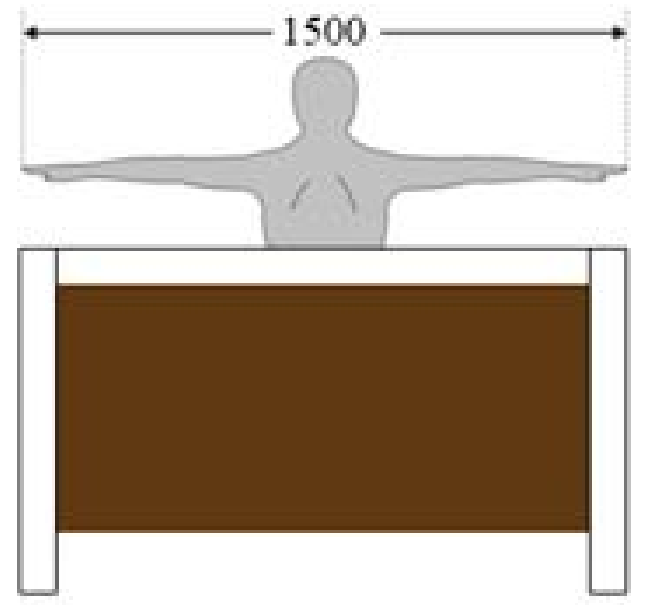

Gambar 3. Rentang kedua tangan

Antropometri yang digunakan untuk menentukan panjang meja adalah jarak bentang dari ujung jari tangan kiri ke kanan. Jenis antropometri yang digunakan untuk kelompok pria adalah $50 \%$ persentil, yaitu $1.663 \mathrm{~mm}$. Maka ditentukan panjang meja 1.500 dikarenakan menyesuaikan ukuran luas ruangan dan permintaan pengguna. Berdasarkan data jenis dan fasilitas meja kerja dijelaskan bahwa tinggi meja kerja pada umumnya berkisar $180 \mathrm{~cm}$ dan dari data antropometri ruang menurut Panero dan Zelnik pada disebutkan bahwa panjang meja 
Vol. 2, No. 2, April 2015

bagian depan berkisar antara 152,4 - 182,9

cm dan panjang meja bagian samping berkisar antara 76,2-121,9 cm. Jadi, panjang produk meja kerja bagian depan yang dirancang tidak kurang dari $150 \mathrm{~cm}$ dan tidak lebih dari 182,9 cm dan panjang meja bagian samping boleh kurang dari $90 \mathrm{~cm}$ dan tidak lebih dari 121,9 cm.

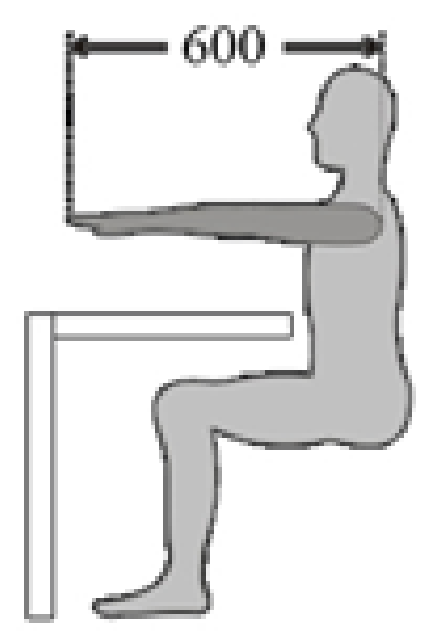

Gambar 4. Rentang tangan ke depan

Antropometri yang digunakan untuk menentukan lebar meja adalah jarak genggaman tangan ke punggung pada posisi tangan ke depan. Jenis antropometri yang digunakan untuk kelompok pria 50\% persentil, yaitu $708 \mathrm{~mm}$. Maka ditentukan lebar meja $650 \mathrm{~mm}$ dikarenakan menyesuaikan lebar ruangan penempatan meja. Berdasarkan data antropometri ruang menurut Panero dan Zelnik disebutkan bahwa lebar meja bagian depan berkisar antara 76,2-91,4 cm dan lebar meja bagian samping berkisar antara 45,7 - 55,9 cm. Jadi, lebar meja bagian depan tidak kurang dari $60 \mathrm{~cm}$ dan lebar meja bagian samping tidak kurang dari $40 \mathrm{~cm}$.
Antropometri yang digunakan untuk menentukan lebar ruang kaki pada kolong meja kerja adalah lebar panggul. Jenis antropometri yang digunakan untuk kelompok pria 95\% persentil, yaitu $371 \mathrm{~mm}$. Maka ditentukan lebar ruang kaki meja kerja $400 \mathrm{~mm}$. Berdasarkan data antropometri posisi duduk menurut Panero dan Zelnik disebutkan bahwa rentang/lebar panggul berkisar 43,4 cm. Jadi, lebar panggul untuk menentukan lebar ruang kaki pada kolong meja tidak kurang dari $40 \mathrm{~cm}$ dan tidak lebih dari 43,4 cm.

Antropometri yang digunakan untuk menentukan kedalaman ruang kaki pada meja kerja adalah jarak dari pantat ke lutut. Jenis antropometri yang digunakan untuk kelompok pria 50\% persentil, yaitu 545 $\mathrm{mm}$. Berdasarkan data antropometri ruang menurut Panero dan Zelnik disebutkan bahwa jarak pantat-lutut berkisar 57,1 cm. Jadi, jarak pantat-lutut untuk menentukan kedalaman ruang kaki pada kolong meja tidak kurang dari 53,7 cm dan tidak lebih dari 57,1 $\mathrm{cm}$.

Analisis konfigurasi dilakukan guna mendapatkan susunan dari tiap-tiap komponen yang terdapat pada desain meja kerja ketua Kurusan Desain Politeknik Negeri Samarinda. Adapun komponen yang terdapat pada produk adalah: (1) Lemari untuk menyimpan berkas/dokumen penting, (2) Laci untuk menyimpan alat tulis kantor, (3) Space untuk area kerja laptop/komputer dan printer, (4) Area datar untuk meletakkan aksesoris pajangan seperti vas bunga, jam dan lain-lain. Dari beberapa alternatif 
Dwi Cahyadi, Arfandi, Desain Meja Ketua Jurusan Desain Politeknik Negeri Samarinda

konfigurasi, setelah dianalisis pilihan jatuh pada konfigurasi gambar 5. Alasannya karena konfigurasi ini menempatkan peletakkan rak, laci, printer, kotak penyimpanan alat tulis kantor dan ruang untuk kaki lebih efisien dan lebih nyaman.

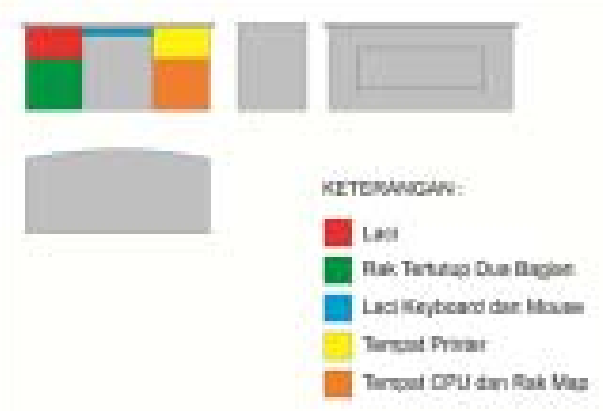

Gambar 5 Alternatif konfigurasi terpilih

Analisis sistem dilakukan guna menentukan sistem apa yang akan dipakai pada produk meja, sehingga akan memudahkan dalam aktivitas pengguna ketika akan menggunakan produk ini. Berikut adalah sistem-sistem yang akan digunakan dan di mana saja sistem-sistem itu diaplikasikan:

\section{Sistem Sambungan Paku dan}

Sekrup. Sistem sambungan menggunakan paku yang ada pada produk ini terdapat pada bagianbagian yang terpisah, antara kaki meja dengan badan meja dan lainlain yang diperlukan untuk membuat sebuah rangka meja kerja. Alat yang digunakan untuk penyambunganpenyambungan struktur tersebut menggunakan paku dengan berbagai macam ukuran. Sedangkan sekrup digunakan untuk pemasangan rel laci.
2. Sistem Geser. Sistem geser yang digunakan pada produk meja kerja ini adalah rel mekanik yang akan diaplikasikan untuk komponen laci meja.

3. Rel Mekanik. Sistem geser menggunakan rel mekanik yaitu rel yang dibuat khusus dari kombinasi bahan logam, plastik atau karet dan didesain sedemikian rupa untuk meningkatkan utilitas kotak laci. Alasan mengapa rel kayu tidak digunakan pada merja kerja ini adalah sistem rel kayu hanya diberikan landasan kayu di bagian bawah laci sebagai rel, maka ketika kotak laci dibuka lebih dari setengah bagian panjang laci mengakibatkan berat kotak laci menjadi tidak seimbang dan membuat kotak laci mudah terjatuh keluar dari lubang laci di furniture.Konstruksi seperti ini lebih baik bagi konsumen/pemakai furniture karena tidak perlu menunduk untuk melihat bagian kotak laci lebih dalam dan tidak perlu kuatir kotak laci akan terjatuh.

4. Sistem Lipat. Sistem lipat yang digunakan pada produk meja kerja ini adalah sistem engsel yang akan diaplikasikan untuk pintu lemari meja adalah Engsel Sendok. Jenis engsel ini digunakan/dipilih karena memiliki kelebihan yaitu pemasangan yang mudah dan cepat, sangat fleksibel dalam arti mudah disesuaikan setelah pemasangan dengan menggunakan 
Vol. 2, No. 2, April 2015

dua buah baut yang tersedia pada setiap engsel. Dilihat dari segi kekuatan, kemudahan produksi, dan kesesuaian konsep engsel ini memiliki nilai tinggi dari beberapa jenis engsel lainnya. Untuk jenis engsel lainnya tidak digunakan/diplih karena ada beberapa kelemahan pada engsel lainnya. Kelemahan butt engsel adalah kurang fleksibel karena tidak bisa disesuaikan lagi setelah dipasang. Selain itu pemasangan engsel ini kurang praktis karena harus membuat takikan (mortise) pada daun pintu atau kusen. Untuk jenis engsel kupukupu memiliki kekurangan yaitu bentuknya yang tipis dan biasanya dipakai untuk beban yang tidak terlalu berat misalnya untuk jendela, lemari loker, peti dan sebagainya. Sedangnkan kelemahan engsel piano adalah sangat jarang digunakan karena jenis engsel ini sering digunakan pada benda yang tidak terlalu berat seperti jendela, lemari atau pintu yang dengan material kayu triplek atau kayu lapis.

Material yang digunakan pada meja kerja ini adalah multiplek/plywood . Multiplek merupakan kayu olahan yang relatif lebih kuat dibanding jenis kayu olahan lainnya seperti hdf, mdf, blockboard atau partikel board. Bahan dasar plywood adalah kulit kayu yang berlapis-lapis dan dipress, sedangkan mdf atau hdf adalah serbuk kayu halus yg diproses menyerupai bahan kertas yg tebal dan solid. Multiplek memiliki kualitas lebih baik dibanding jenis kayu olahan lainnya. Tekstur lapisan kayunya lebih rapat, sehingga memiliki kekuatan yang lebih baik dan daya tahan terhadap air lebih kuat. Urutan berikutnya dari yang lebih kuat ke yang kurang kuat adalah bahan plywood/multiplek, bloackboard, MDF, dan particle board.

Untuk material stainless steel digunakan untuk bagian penopang yang terdapat pada kedua sudut bagian depan meja. Dari beberapa alternatif antara lain; Stainless steel, pipa besi dan almunium, Material stainless steel dipilih karena sudah sesuai dengan bentuk dan sesuai dengan kesesuain konsep desain pengguna. Untuk material lain seperti besi dan almunium tidak digunakan/dipilih karena belum memenuhi kesesuaian konsep desain pengguna.

Dari kedua alternatif Finishing di bagian teori yaitu menggunakan HPL atau cat duco maka finishing yang digunakan pada meja kerja ini adalah cat duco, karena cat duco memberikan kesan yang rapi dan bersih. Kesesuain konsep dengan pengguna juga merupakan faktor yang mendorong terpilihnya finishing ini. Warna cat pada meja kerja ini adalah abu-abu.

Analisis bentuk dilakukan guna menentukan gaya desain apa yang sesuai dengan konsep yang diambil dan akan diaplikasikan pada produk meja kerja. Dengan konsep desain portable, yaitu bisa dilepas-pasang.

Melihat dari analisis segmentasi dan konsep yang dipilih berdasarkan keinginan 
Dwi Cahyadi, Arfandi, Desain Meja Ketua Jurusan Desain Politeknik Negeri Samarinda pengguna, maka gaya desain yang digunakan Selanjutnya alternatif terpilih adalah modern. Dalam gaya desain modern bentuk ini lebih mengarah ke gaya desain Modern minimalist, karena gaya modern adalah gaya desain yang simple, bersih, fungsional, stylish, dan juga sesuai dengan konsep desain pengguna. Untuk gaya desain bauhauss tidak digunakan/dipilih karena meja kerja ini tidak sepenuhnya dibuat dengan menggunakan mesin, sedangkan gaya desain de stijl tidak digunakan/dipilih karena warna pada produk ini tidak ada yang menggunakan warna primer (merah, kuning, biru).

Warna yang digunakan untuk produk meja kerja ini adalah warna abu-abu. Karena warna abu-abu dapat memberi kesan elegan dan sudah memenuhi kesesuaian konsep desain pengguna.

Berdasarkan dari analisis dari beberapa alternatif desain yang ada, disimpulkan desain alternatif yang ditunjukkan dalam gambar 6 terpilih untuk perancangan meja kerja ketua Jurusan Desain Politeknik Negeri Samarinda.

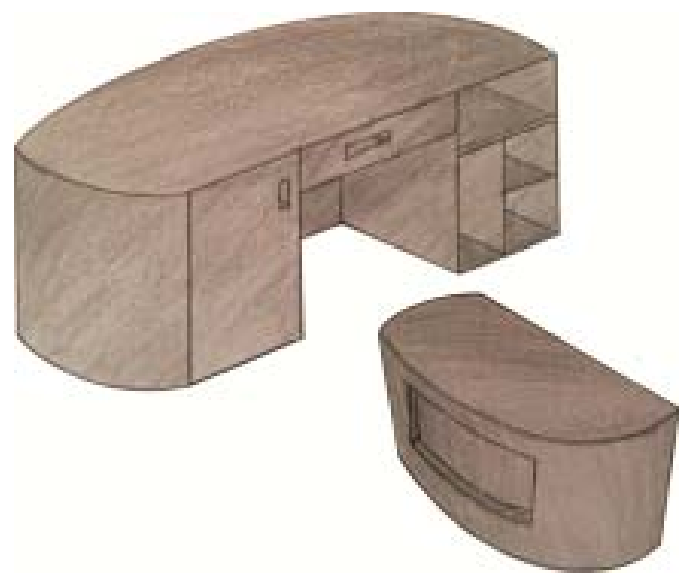

Gambar 6. Alternatif Desain terpilih 


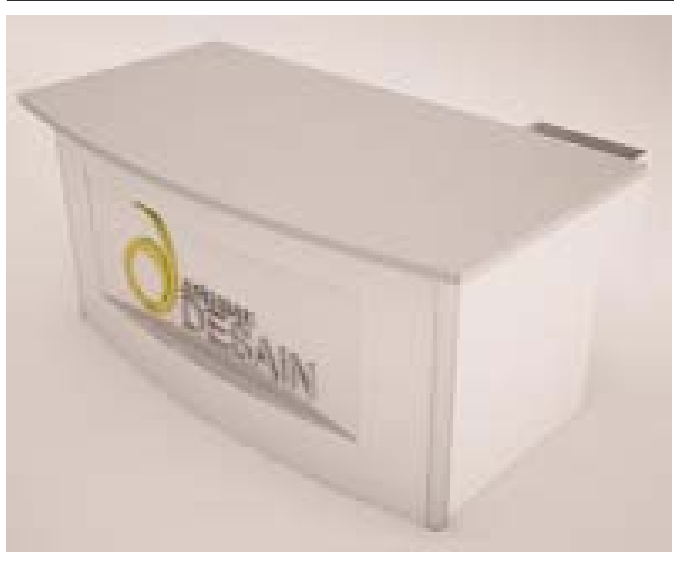

Gambar 8. Desain Akhir

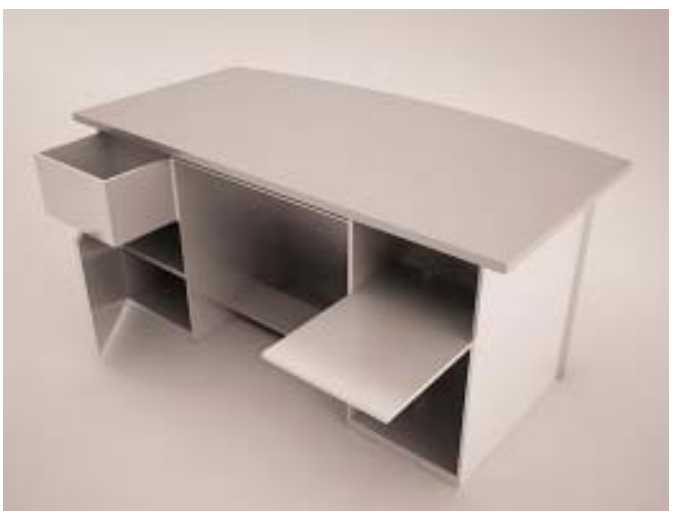

Gambar 9. Desain Akhir

\section{Kesimpulan}

Hasil dari perancangan dan pembuatan “Desain Meja Kerja Ketua Jurusan Desain Politeknik Negeri Samarinda”, yaitu meja kerja yang dikhususkan untuk Ketua Jurusan Desain ini dirancang sesuai keinginan pengguna baik dari segi fungsi dan estetis. Produk merupakan inovasi produk fungsional dari meja kerja sebelumnya dengan fasilitas seperti rak untuk penyimpanan folder, kertas/ map, drawing book A3, laci dan lemari yang diperlukan dan lebih estetis dari bentuk sekatsekat yang dibuat pada bagian rak. Suasana dan tempat kerja haruslah nyaman. Karena ruang kantor yang sempit, maka ukuran dan bentuk dibuat menyesuaikan ruang dan fasilitas kebutuhan yang diperlukan pengguna.

Saran yang dapat diberikan adalah untuk di masa mendatang jika produk ini akan diproduksi secara massal, perlu diadakan redesign untuk inovasi bentuk dengan tambahan fungsi privasi pada meja kerja, serta warna yang lebih beragam sesuai keinginan pasar dan ukuran yang disesuaikan dengan ruangan standar kantor publik lainnya. Selain itu, diadakan perbaikan pada sistem putar dibagian rak agar gesekan putarannya lebih lancar dan kuat. 
Dwi Cahyadi, Arfandi, Desain Meja Ketua Jurusan Desain Politeknik Negeri Samarinda

\section{DAFTAR PUSTAKA}

Alfiago, S. (2012). Elemen Mesin (Sambungan Mur Baut). 06 Agustus, 2015. http:// ren3energi.blogspot.com/2012/09/elemen-mesin-sambungan-mur-baut.html

Bhavati, A. (2014). Jenis-Jenis Perlengkapan Kantor. 13 Februari, 2015. http:// anugerahdino.blogspot.com/2014/02/jenis-jenis-perlengkapan-kantor.html

Erniathi, D.A. (2011). Bahan: Mengenal Empat Jenis Kayu Olahan. 20 Februari, 2015. http://www.derumi.net/2011/mengenal-empat-jenis-kayu-olahan-bahan/

Hidayati, Z. (2006). Modul Bahan Ajar: Sejarah dan Perkembangan Desain. Samarinda: Departemen Pendidikan Nasional Politeknik Negeri Samarinda.

Hindarto, M.P. (2006). Warna Untuk Desain Interior. Yogyakarta: Penerbit Media Pressindo.

Inu, O. (2013). Fungsi Meja Kantor Dan Cara Memilihnya. 09 Februari, 2015. http:/ /rajabrankas.blogspot.com/2013/02/fungsi-meja-kantor-dan-cara-memilihnya.html

Khedanta. (2011). Jenis Engsel. 28 Maret, 2015. https://khedanta.wordpress.com/2011/ 08/02/jenis-engsel/

Kurniawan, D.P. (2013). Plus Minus Furniture Lapis HPL. 12 Maret, 2015. http:// dhianfurniture.blogspot.com/2013/12/plus-minus-furniture-lapis-hpl.html

Lawson, B. (1990). How Designer Think(2rd ed). The University Press.

Marizar, E.S. (2005). Designing Furniture. Yogyakarta: Penerbit Media Pressindo.

Media Informasi Teknik Industri. (2011). Materi kuliah Elemen mesin - Sambungan Sekrup. 01 April, 2015. http://fteknikindustri.blogspot.com/2011/11/materi-kuliah-fisikadasar-sambungan.html

Nurmianto, E. (1991). Ergonomi: Konsep Dasar dan Aplikasinya (2rd ed). Surabaya: Penerbit Guna Widya.

Oscar. (2011). Jenis-Jenis Kayu Olahan. 24 Februari, 2015. http:// oscarfurniturestore.com/2011/12/jenis-jenis-kayu-olahan/ 
Palgunadi, B. (2008). Desain Produk 3: Mengenal Aspek Disain. Bandung: Penerbit ITB.

Panero, J., \& Zelnik, M. (2003). Dimensi Manusia \& Ruang Interior: Buku Panduan Untuk Standar Pedoman Perancangan. Jakarta: Penerbit Erlangga.

Pramono, E. (2013). Mengenal Berbagai Tipe Engsel. 28 Maret, 2015. https:// andalan68.wordpress.com/tag/engsel-sendok/

Rizqi, M. G. (2012). Tentang Finishing Semprot Cat Duco. 12 Maret, 2015. http:// www.alliafurniture.com/2012/06/tentang-finishing-semprot-cat-duco.html

Royan, F.M. (2007). Smart Launching New Product. Jakarta: Penerbit PT Elex Media Komputindo.

Suyanto, M. (2004). Analisis dan Desain Aplikasi Multimedia Untuk Pemasaran.

Tim Penyusun Kamus Pembinaan dan Pengembangan Bahasa (2rd ed). (1999). Kamus Besar Bahasa Indonesia. Jakarta: Balai Pustaka.

Wijayanti, S.E. (2011). Karya Ilmiah Mengenai Segmentasi Pasar. Yogyakarta: Ebook.

Wong, W. (1998). Beberapa Asas Merancang Trimatra (Adjat Sakri, Penerjemah). Bandung: Penerbit ITB.

Yasyin, S. (Ed.). (1995). Kamus Pintar Bahasa Indonesia. Surabaya: Penerbit Amanah Surabaya.

Dewy Ningsih M (2015) Desain Meja Kerja Ketua Program Studi Desain Produk Jurusan Desain Politeknik Negeri Samarinda, Laporan Tugas Akhir pada Jurusan Desain Politeknik Negeri Samarinda.

Kamus Besar Bahasa Indonesia Online, Badan Pengembangan dan Pembinaan Bahasa, Kemdikbud 29 Februari, 2016, $\underline{\text { htps://kkbi.web.id }}$ 